\section{Original Research}

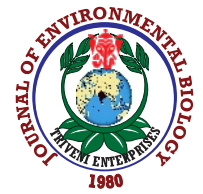

DOI : http://doi.org/10.22438/jeb/42/4/MRN-1682
Journal website : www.jeb.co.in $\star$ E-mail : editor@jeb.co.in Journal of Environmental Biology
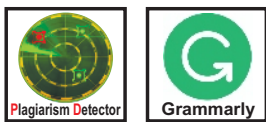

\title{
Systemic mycobacteriosis along with concurrent fibroma in Goldfish, Carassius auratus from India
}

\author{
T. R. Swaminathan', N. Sood", P. K. Pradhan', M. K. Yadav', R. Kumar', D. K. Verma², R. Pal', A. Dharmaratnam ${ }^{1}$ and N. K. Sood ${ }^{3}$ \\ 'Peninsular and Marine Fish Genetic Resources Centre, ICAR-NBFGR, CMFRI Campus, Kochi-682 018, India \\ ${ }^{2}$ Fish Health Management and Exotics Division, ICAR-National Bureau of Fish Genetic Resources, Lucknow-226 002, India \\ ${ }^{3}$ Department of Teaching Veterinary Clinical Complex, Guru Angad Dev Veterinary and Animal Sciences University, Ludhiana-141 012, India \\ *Corresponding Author Email : sood_neeraj@rediffmail.com
}

\section{Abstract}

Aim: Goldfish (Carassius auratus L.), a freshwater fish belonging to the family Cyprinidae, is an important ornamental fish species in the world. Herewith, we report a case of systemic mycobacteriosis along with concurrent fibroma in goldfish.

Methodology: The protruding mass and internal organs exhibiting lesions were collected for histopathology and molecular diagnosis. The sections of cutaneous mass were stained with haematoxylin and eosin $(\mathrm{H} \& \mathrm{E})$ and Masson trichrome, whereas sections from spleen as well as kidney were stained with $\mathrm{H} \& \mathrm{E}$ and Ziehl-Neelsen. For identifying the etiological agent, $16 \mathrm{~S}$ rRNAgene fragment was amplified and sequenced, using genus-specific primers for Mycobacterium sp.

Results: In histopathology, multiple granulomas could be observed in kidney and spleen sections. Importantly, typical acid-fast bacilli were demonstrated in granulomas in spleen. The sequence of $16 \mathrm{~S}$ rRNA gene fragment amplified from spleen and kidney showed maximum similarity to Mycobacterium stomatepiae. Besides, the histopathological characteristics of the protruding mass were consistent with cutaneous fibroma.

Interpretation: These findings assume significance as several Mycobacterium species, including the current one from ornamental fish are reported to be of zoonotic significance.

Key words: Fibroma; Goldfish; Granuloma; Mycobacteriosis, 16S rRNAgene

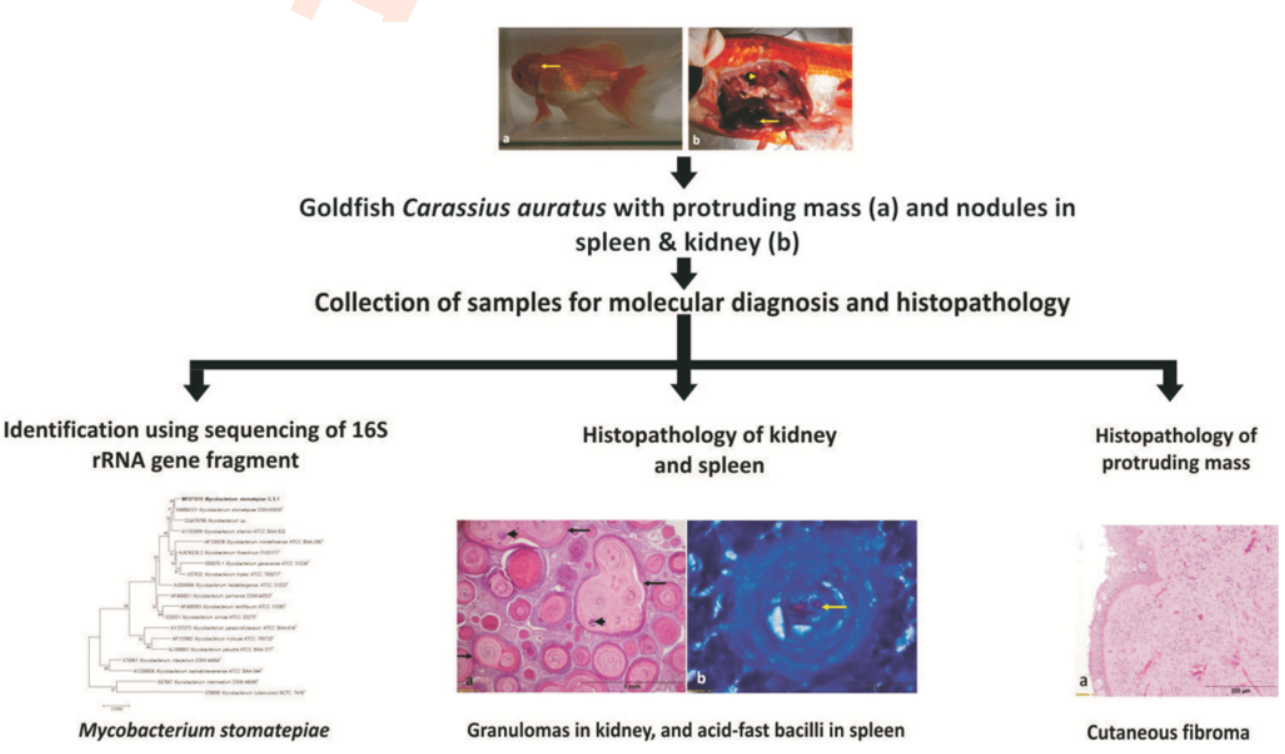

How to cite : Swaminathan, T.R., N. Sood, P.K. Pradhan, M.K. Yadav, R. Kumar, D.K. Verma, R. Pal, A. Dharmaratnam and N.K. Sood: Systemic mycobacteriosis along with concurrent fibroma in Goldfish, Carassius auratus from India. J. Environ. Biol., 42, 1019-1025 (2021). 


\section{Introduction}

Fish mycobacteriosis is a common bacterial disease affecting farmed and wild fishes worldwide, including India (Gauthier and Rhodes, 2009; Das et al., 2016; Gokulraj et al., 2019). The disease is caused by diverse Mycobacterium species, commonly referred as non-tuberculous mycobacteria. Some of the commonly associated species include $M$. fortuitum, $M$. marinum and M. chelonae (Decostere et al., 2004), but several other spp., namely M. montefiorense (Levi et al., 2003) M. stomatepiae, M. angelicum (Pourahmad et al., 2008) and M. gordonae (Kusar et al., 2017) have also been associated with fish mycobacteriosis. Over 150 fish species are reported to be affected by this disease (Decostere et al., 2004). Many of these fishes are long-term carriers of mycobacteria before any clinical signs of the disease are detected grossly, and therefore, may transmit the infection to other fish in aquarium, tank or pond (Lowry and Smith, 2007). Importantly, mycobacteria, causing infection in fishes, can also result in chronic illness particularly in immuno compromised individuals. These bacteria often affect people handling affected fish and the resultant infections are called fish handler's disease or fish tank granuloma. In human beings, the infections usually develop in extremities and are either ulcerative or raised granulomatous nodules (Kiesch, 2000).

Goldfish (Carassius auratus L.), a freshwater fish of the Cyprinidae family, is an important ornamental fish species (Tu et al., 2015). It is widely preferred by hobbyists because of morphological varieties, attractiveness, variety of colors and high tolerance to environmental demands. The healthy offsprings of goldfish are considered essential for meeting the market demand (Gumus et al., 2016). However, goldfish is susceptible to a number of pathogens, especially viruses, bacteria and parasites (Verma et al., 2015; Roohi et al., 2016; Sahoo et al., 2016). Amongst the bacterial diseases, mycobacteriosis is quite frequent in goldfish (Francis-Floyd, 2011) and several mycobacterial species namely $M$. gordonae, $M$. chelonae, $M$. marinum (Pate et al., 2005) and M. fortuitum (Uma and Ronald, 2016) are reported from this ornamental fish. The typical lesions in diseased fish include systemic granulomas, as observed in human tuberculosis (Nau et al., 1997). Besides, several neoplasms, including fibroma, leiomyoma, infiltrative lipoma have also been reported in ornamental fishes (Constantino et al., 1999; Sood et al., 2017). The diseases and tumours are responsible for decreased attractiveness of ornamental fishes due to loss of colour, scales, fins and unsightly lesions.

In view of the above, the present study reports a case of systemic mycobacteriosis along with concurrent fibroma in goldfish.

\section{Materials and Methods}

A goldfish (body weight- $90 \mathrm{~g}$; length- $19 \mathrm{~cm}$ ) having a mass on dorsal region of operculum on left side, was brought to
Fish Health Management Laboratory of Peninsular and Marine Fish Genetic Resources Centre, ICAR-NBFGR, Kochi from an ornamental fish farm in Kerala. The fish was euthanized with an overdose of MS222 (Sigma-Aldrich, St. Louis, USA) and necropsy was carried out to record the gross lesions in internal organs. The cutaneous mass along with spleen and kidney were collected in RNA later and 10\% neutral buffered formalin (NBF). The samples fixed in NBF were routinely processed for histopathology, and tissue sections (5um thickness) were stained with haematoxylin and eosin ( $H$ and E). Sections of the cutaneous mass were stained with Masson trichrome whereas sections from spleen and kidney were stained with Ziehl-Neelsen following Luna (1968).

DNA from above organs of the affected fish was extracted using a DNeasy Blood and Tissue Kit (Qiagen, Hilden, Germany), and mycobacterial $16 \mathrm{~S}$ rDNA was detected using genus-specific primers T39 (GCGAACGGGTGAGTAACACG) and T13 (GCACACAGGCCACAAGGGA), as per Talaat et al. (1997). The PCR products were purified using Gel Extraction Kit (Fermentas Life Sciences, Vilnius, Lithuania) and cloned into pTZ57R/T vector (Fermentas Life Sciences), followed by transformation into Escherichia coli DH5a. The recombinant plasmids were sequenced using M13 forward and reverse primers. The sequences of amplicons from spleen and kidney were compared, and species-level identification was based on the maximum identity combined with greatest sequence coverage in NCBI Blast. Mycobacterium species with higher similarity were selected for homology assessment. All the sequences were aligned with the CLUSTALW programme in MEGA 7.0 software (Kumar et al., 2016) and trimmed for equal length (924bp). Phylogenetic tree was constructed using Neighbor-joining method (Saitou and Nei, 1987) and pair-wise sequence similarity was calculated with closest Mycobacterium species. Further, bootstrap value of 1000 was used to determine the confidence interval of the resultant tree. M. tuberculosis NCTC $7416^{\top}$ (X58890) was used as outgroup.

\section{Results and Discussion}

The mass on the operculum measuring approximately 1 $\mathrm{cm}$ diameter protruded from the surface on the operculum, and was multinodular, yellowish-pale, spherical and firm. The cut surface was whitish-grey and consisted of variably-sized distinct lobules. Histopathologically, the cutaneous mass was multilobular and composed of wavy and interlacing bundles of collagen intermingled with fibroblasts. The neoplastic fibroblasts were fusiform with ovoid nuclei and abundant cytoplasm. Their nucleoli were indistinct, and mitotic figures were not observed. The cells were separated by abundant ground substance, and numerous congested blood vessels along with multifocal haemorrhages were observed in the tumour tissue. Marked vacuolar degeneration and sloughing were observed in cutaneous epithelium overlying the mass (Fig. 1a). Masson 
trichrome staining showed abundant collagen in interlacing bundles (blue) whereas the nuclei of fibroblasts stained red (Fig. $1 \mathrm{~b})$. On the basis of lack of significant cellular and nuclear atypia and anaplasia of neoplastic fibroblasts, the tumour was identified as fibroma. The fibromas in fishes are most common in the dermis and usually occur singly (Wongsathein, 2006; Handharyani et al., 2008), as in this study. The histopathological alterations, namely fusiform cells with ovoid nuclei, indistinct nucleoli, lack of mitotic figures and presence of abundant ground substance in the affected goldfish are in accordance with those reported earlier in fishes with fibroma (Lopez and Raibaut, 1981; Constantino et al., 1999; Sahoo et al., 2017). The tumour in this study was well vascularized and lacked inflammatory response as described earlier (Harshbarger, 1972). In contrast to the present findings, perivascular infiltration of mononuclear inflammatory cells was observed previously in the dermis of goldfish with fibroma (Lopez and Raibaut, 1981). It is to be noted that the cause of fibroma development is still unclear though a few environmental factors and infectious agents, particularly retroviruses (Francis et al., 1993) and nematode (Overstreet and Edwards, 1976) have been incriminated. In this study, the infectious etiology was not suspected due to lack of inflammatory reaction as well as absence of bacteria and parasites in histological sections. Therefore, it was assumed that environmental factors could be
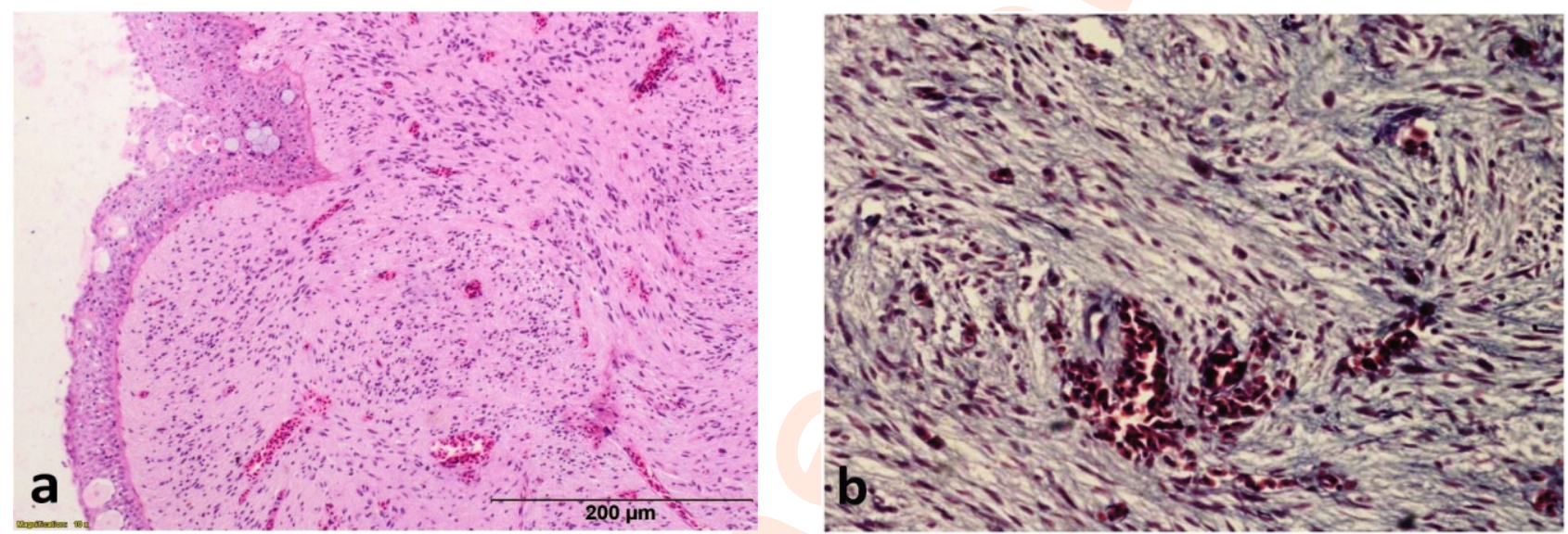

Fig. 1 : (a) Overview of the vascular dermal fibroma with overlying skin epithelium and marked vacuolar degeneration. (b) Higher magnification revealing whorling pattern and mature fibroblasts more conspicuously. The dermal mass did not show significant nuclear pleomorphism and anaplasia and there was absence of prominent nucleoli as well as mitoses, consistent with fibroma (Masson's trichrome X40X).
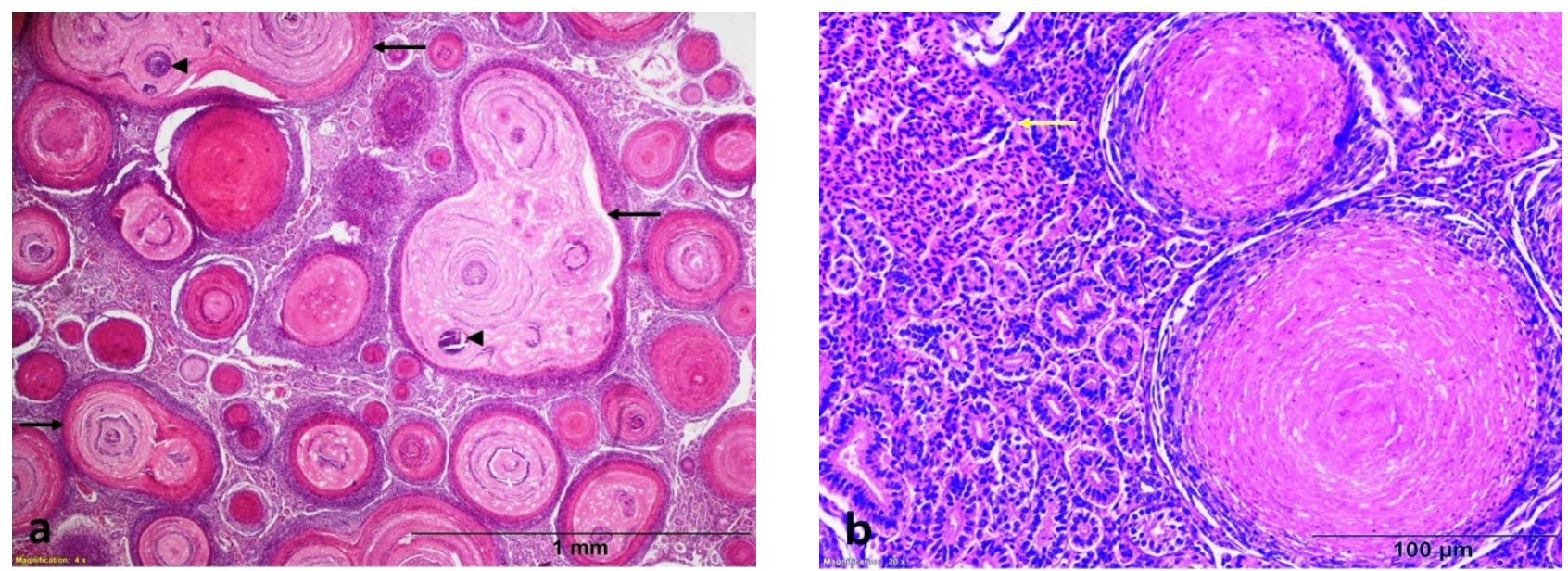

Fig. 2 : (a) A section of the goldfish kidney showing multiple caseo-calcareous granulomas, surrounded by fibrosis, replacing most of the renal parenchyma. Some of the granulomas were coalesced (arrows) and calcified (arrowheads). (b) A higher magnification revealed caseous necrosis in the centre surrounded by epithelioid cells and fibroblasts at the margins. Haemorrhages were also seen in the renal parenchyma (arrows). 

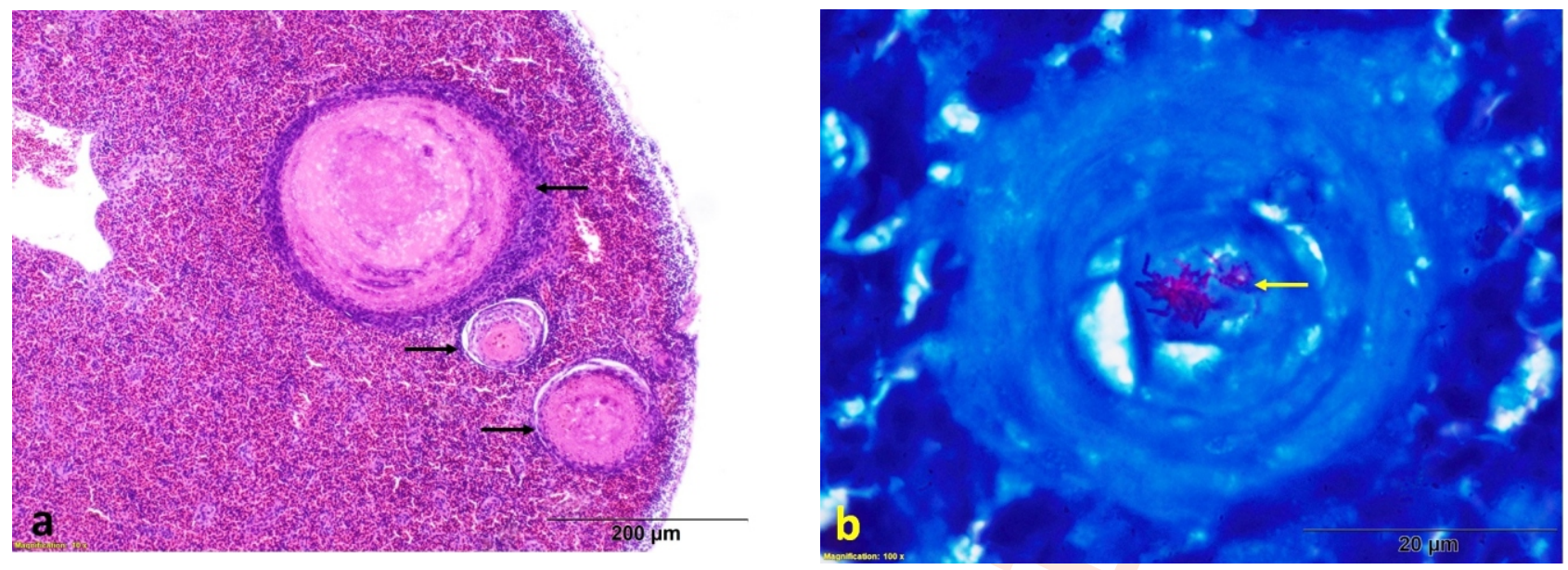

Fig. 3 : (a) A section of the goldfish spleen showing granulomas of varying sizes. The granulomas displayed caseous necrosis in the centre surrounded by epithelioid cells. (b) Ziehl- Neelsen staining showing typical acid-fast bacilli (arrow) in centre of granuloma in spleen.

the cause of fibroma, as reported earlier (Lopez and Raibaut, 1981).

On post-mortem, spleen exhibited multiple white nodules of varying sizes on its surface whereas whole of the kidney had variable sized grayish-white nodules on its gross and cut surface. In kidney and spleen sections, many necrotizing granulomas were observed replacing most of their parenchyma, particularly in kidney (Fig. 2a,b). The granulomas in kidneys had a central core of caseous necrosis surrounded by macrophages, epithelioid cells and fibrous connective tissue. Dystrophic calcification was observed in the necrotic areas of some of these granulomas (Fig. 2a). In places, these granulomas were seen coalescing. In spleen, macrophage aggregation without necrosis was more evident representing early granuloma formation, and fewer necrotizing granulomas, at times, having acid-fast bacilli were also observed (Fig. 3a,b). Acid-fast bacilli, however, were not seen in kidney sections on special staining. In the present case, the lesions in kidney and spleen of goldfish were clearly suggestive of systemic mycobacteriosis. Mycobacteriosis is a common bacterial disease affecting ornamental fish (Noga, 2010; Delghandi et al., 2020; Puk and Guz, 2020), and goldfish is reported to be more prone to mycobacteriosis (Francis-Floyd, 2011). Importantly, systemic granuloma formation is the characteristic histopathological alteration of chronic mycobacterial infection in fish (Talaat et al., 1998; Martınez-Lara et al., 2021) and several non-tuberculous mycobacteria, namely M. marinum, M. fortuitum, M. chelonae and M. gordonae have been incriminated as etiological agent of mycobacteriosis in goldfish (Pate et al., 2005). Caseous necrosis, as observed in the centre of granulomas in the affected goldfish, has been observed earlier in naturally infected fish (Balouet and Baudinlaurencin, 1986) and also following experimental infection (Talaat et al., 1998). Besides, calcification and fibrosis are suggestive of healing and indicate an attempt of host to clear the infection. Furthermore, the multi-centric granulomas in this study were similar to those noticed at late-stage human tuberculosis (Ulrichs and Kaufmann, 2006). In spleen, melanomacrophage centres (MMCs) were observed in close proximity of granulomas, which is in accordance with earlier report in goldfish (Talaat et al., 1998). The MMCs, considered primitive analogues of germinal centres observed in mammals, may develop in association with chronic inflammatory conditions and act as focal depositories of resistant intracellular bacteria (Agius and Roberts, 2003).

PCR products of 924 bp were amplified from DNA extracted from both the organs of affected goldfish, using genusspecific primers of Mycobacterium. The sequenced products from spleen and kidney were $100 \%$ identical to each other, therefore, the sequence from spleen was submitted to GenBank under the accession number MF871619. The nucleotide BLAST of the sequence revealed maximum similarity $(99.89 \%)$ and $100 \%$ query coverage with $M$. stomatepiae. CLUSTALW alignment of the sequence with other reference Mycobacterium species revealed that goldfish spleen amplicon showed maximum similarity (99.9\%) with $16 \mathrm{~S}$ rRNA of Mycobacterium stomatepiae (AM884331). Furthermore, the phylogenetic analysis suggested that the mycobacterial amplicon from goldfish spleen forms a distinct clade with non-tuberculous slow growing species of the genus Mycobacterium (Fig. 4). In the affected goldfish, the partial 16S rRNA gene sequence from both the organs showed maximum homology with Mycobacterium stomatepiae, which was first reported from cichlid Stomatepia mariae held at London Zoo Aquarium, United Kingdom (Pourahmad et al., 2008). Morever, it is important to mention that infection due to $M$. stomatepiae has also been observed in human beings (Shahraki et al., 2015), which suggests that these mycobacteria can be zoonotic. 


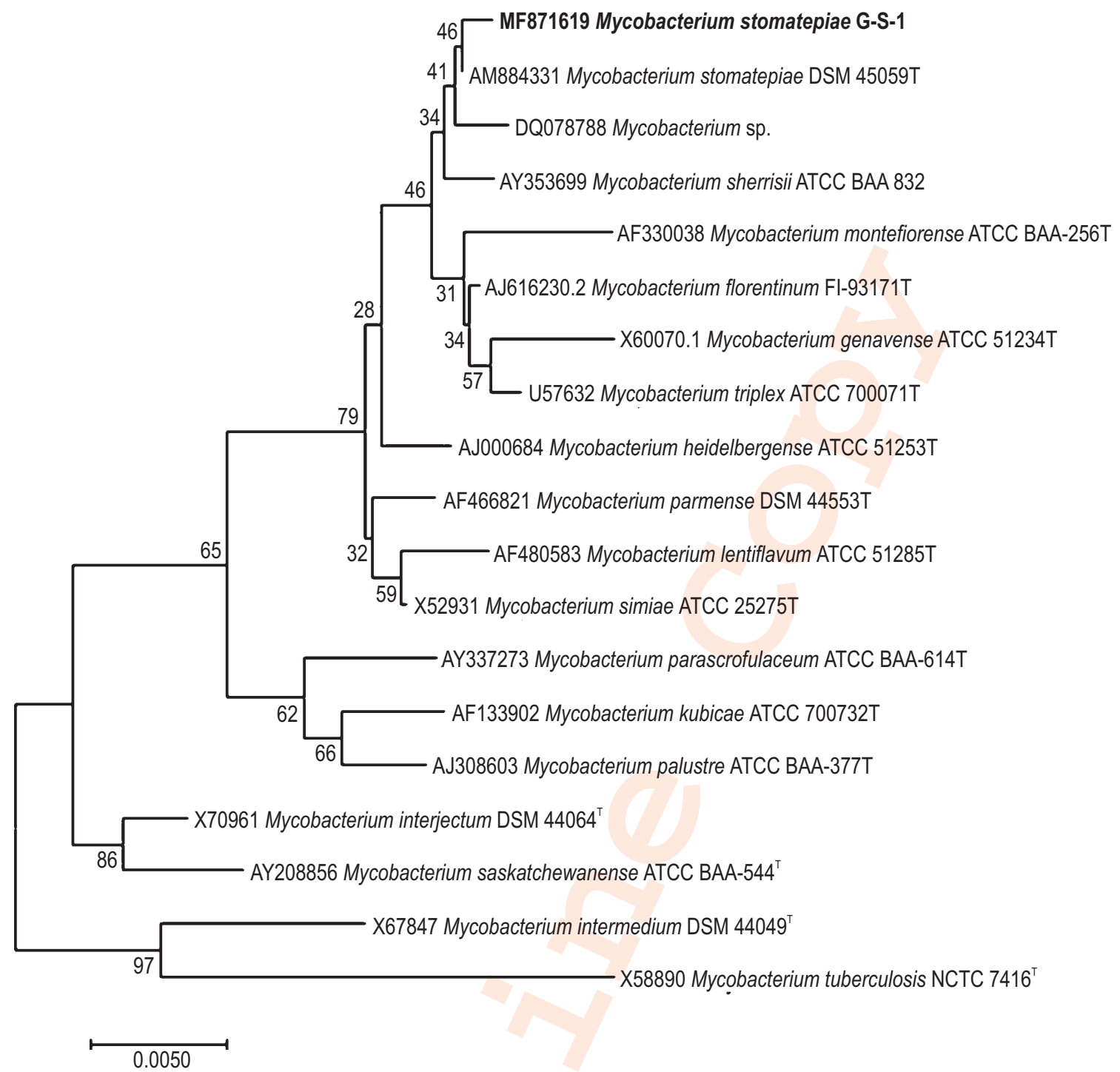

Fig. 4 : Phylogenetic relationship of Mycobacterium stomatepiae based on 16S rRNA gene sequences inferred using the Neighbor-joining method. Statistical confidence in tree branches was generated by performing 1000 bootstrap replicates. The tree is drawn to scale, with branch lengths measured as the number of substitutions per site.

The present study forms the first report of systemic mycobacteriosis caused by $M$. stomatepiae, with concurrent dermal fibroma in goldfish from India. The present findings assume significance as several mycobacterial species, including the current one from ornamental fish are reported to be zoonotic (Lescenko et al., 2003). Besides, in humans, there are many reports of mycobacterial infections that have been correlated with handling of ornamental fish (Casal and Casal, 2001). Hence, people need to be educated about health risks of handling aquarium fishes so as to prevent transmission of mycobacterial infection from fish to human beings.

\section{Acknowledgments}

The authors wish to thank Director, ICAR-NBFGR and Deputy Director General (Fy. Sc.), ICAR for the support, guidance and encouragement. The authors are also thankful to NFDB, Hyderabad and Department of Fisheries, Ministry of Fisheries, Animal Husbandry and Dairying for the financial support under National Surveillance Programme on Aquatic Animal Diseases.

\section{Add-on Information}

Authors' contribution: N. Sood: Manuscript preparation and finalization, T.R. Swaminathan: Conceptualization, Sample collection, Manuscript preparation, P.K. Pradhan: Critical reviewing the manuscript, M.K. Yadav: Histopathology of the samples, R. Kumar: Sample collection and processing, D.K. Verma: Cloning and molecular confirmation of Mycobacterium sp., R. Pal: Special staining of tissue sections, A. Dharmaratnam: Isolation of nucleic acid and PCR, N.K. Sood: Histopathological 
examination and critical review of the manuscript.

Research content: The research content of manuscript is original and has not been published elsewhere.

\section{Ethical approval: Not applicable}

Conflict of interest: The authors declare that there is no conflict of interest.

\section{Data from other sources: Not applicable}

Consent to publish: All authors agree to publish the paper in Journal of Environmental Biology.

\section{References}

Agius, C. and R.J. Roberts: Melano-macrophage centres and their role in fish pathology. J. Fish Dis., 26, 499-409 (2003).

Balouet, G. and F. Baudinlaurencin: Granulomatous nodules in fish: an experimental assessment in rainbow trout, Salmo gairdneri Richardson, and turbot, Scophthalmus maximus (L.). J. Fish Dis., 9,417-429(1986).

Casal, M. and M.D. Casal: Multicenter study of incidence of Mycobacterium marinum in humans in Spain. Int. J. Tuberc. Lung Dis., 5, 197-199 (2001).

Constantino, F., A.A. de Ocampo and L.J. Garcia-Marquez: Dermal fibroma in goldfish, Carassius auratus (L.). J. Fish Dis., 22, 223226 (1999)

Das, P., T. Saha and T. Sengupta: A detailed report on mycobacteriosis in Pampus argenteus along the coast of Bay of Bengal, West Bengal, India. J. Coast. Life Med., 4, 760-764 (2016).

Decostere, A., K. Hermans and F. Haesebrouck: Piscine mycobacteriosis: A literature review covering the agent and the disease it causes in fish and humans. Vet. Microbiol., 99, 159-166 (2004).

Delghandi, M.R., M. El-Matbouli and S. Menanteau-Ledouble: Mycobacteriosis and infections with non-tuberculous mycobacteria in aquatic organisms: A review. Microorganisms, $\mathbf{8}$, p. 1368 (2020).

Francis, F.R., B. Bolon, W. Fraser and P. Reed: Lip fibromas associated with retrovirus-like particles in angel fish. J. Am. Vet. Med. Assoc., 202, 427-429 (1993).

Francis-Floyd, R.: Mycobacterial Infections of Fish. SRAC Publication, 4706 (2011).

Gauthier, D.T. and M.W. Rhodes: Mycobacteriosis in fishes: A review. Vet. J., 180, 33-47 (2009).

Gokulraj, A., J. Praveenraj, R. Gnanadesikan and U. Arumugam: Mycobacterial infection in ornamental fishes farmed in low saline waters of Tiruvallur District, India. J. Coast. Res., 86, 134-137 (2019).

Gumus, E., B. Aydin and M. Kanyilmaz: Growth and feed utilization of goldfish (Carassius auratus) fed graded levels of brewers yeast (Saccharomyces cerevisiae). Iran. J Fish. Sci., 15, 1124-1133 (2016).

Handharyani, E., H. Hatai, A. Winarto and K. Ochiai: Dermal fibroma in a goldfish: Immunohistochemistry and polymerase chain reaction. Proc. Asian Zoo/Wildl. Med. Cons., 46-47 (2008).
Harshbarger, J.C.: Work of the registry of tumours in lower animals with emphasis on fish neoplasms. Symp. Zool. Soc. Lond., 30, 285-303 (1972).

Kiesch, N.: Aquariums and mycobacteriosis. Rev. Méd. Brux., 21, A255-A256 (2000).

Kumar, S., G. Scecher and K. Tamura: MEGA7: molecular evolutionary genetics analysis version 7 for bigger data sets. Mol. Biol. Evol., 33, 1870-1874 (2016).

Kusar, D., U. Zajc, V. Jencic, M. Ocepek, J. Higgins, M. Zolnir-Dovc and M. Pate: Mycobacteria in aquarium fish: results of a 3-year survey indicate caution required in handling pet-shop fish. J. Fish Dis., 40, 773-784 (2017).

Lescenko, P., L. Matlova, L. Dvorska, M. Bartos, O. Vavra, S. Navratil, L. Novotny and I. Pavlik: Mycobacterial infection in aquarium fish. Vet. Med. (Praha), 48, 71-78 (2003).

Levi, M.H., J. Bartell, L. Gandolfo, S.C. Smole, S.F. Costa, L.M. Weiss, L.K. Johnson, G. Osterhout and L.H. Herbst: Characterization of Mycobacterium montefiorense sp. nov., a novel pathogenic Mycobacterium from moray eels that is related to Mycobacterium triplex. J. Clin. Microbiol., 41, 2147-2152 (2003).

Lopez, A. and A. Raibaut: Multiple cutaneous fibromas in a mullet, Mullet cephalus cephalus L. J. Fish Dis., 4, 169-174 (1981).

Lowry, T. and S.A. Smith: Aquatic zoonoses associated with food, bait, ornamental, and tropical fish. J. Am. Vet. Med. Assoc., 231, 876$880(2007)$

Luna, L.G.: Manual of Histologic Staining Methods of the Armed Forces Institute of Pathology. $3^{\text {rd }}$ Edn., McGraw-Hill, New York (1968).

Martınez-Lara, P., M. Martınez-Porchas, T. Gollas-Galvan, J. Hernandez-Lopez and G.R. Robles-Porchas: Granulomatosis in fish aquaculture: a mini review. Rev. Aquacult., 13, 259-268 (2021).

Nau, G.J., P. Guilfoile, G.L. Chupp, J.S. Berman, S.J. Kim, H. Kornfeld and R.A. Young: A chemoattractant cytokine associated with granulomas in tuberculosis and silicosis. Proc. Natl. Acad. Sci. U.S.A., 94, 6414-6419(1997).

Noga, E.J.: Problem 55: Mycobacteriosis. In: Fish Disease Diagnosis and Treatment. $2^{\text {nd }}$ Edn., Ames, IA: Wiley-Blackwell Publishing, pp. 204-208 (2010).

Overstreet, R.M. and R.H. Edwards: Mesesnchymal tumors of some estuarine fishes of the northern Gulf of Mexico. II. Subcutaneous fibromas in the southerm flounder, Paralichthys lethostigma, and the sea catfish, Arius felis. Bull. Mar. Sci., 26, 41-46 (1976).

Pate, M., V. Jencic, M. Dovc and M. Ocepek: Detection of mycobacteria in aquarium fish in Slovenia by culture and molecular methods. Dis. Aquat. Org., 64, 29-35 (2005).

Pourahmad, F., F. Cervellione, K.D. Thompson, J.B. Taggart, A. Adams and R.H. Richards: Mycobacterium stomatepiae sp nov., a slowly growing, non-chromogenic species isolated from fish. Int. J. Syst. Evol. Microbiol., 58, 2821-2827 (2008).

Puk, K. and L. Guz: Occurrence of Mycobacterium spp. in ornamental fish. Ann. Agric. Environ. Med., 27, 535-539 (2020).

Roohi, J.D., K. Ghasemzadeh and M. Amini: Occurrence and intensity of parasites in goldfish (Carassius auratus L.) from Guilan province fish ponds, North Iran. Croat. J. Fish., 74, 20-24 (2016).

Sahoo, M.K., P. Rajesh Kumar, S. Pattanayak, P.C. Das and P.K. Sahoo: Dermal fibroma in olive barb Systomus sarana (Hamilton, 1822): a case study. Ind. J. Fish., 64, 95-97 (2017).

Sahoo, P.K., T.R. Swaminathan, T.J. Abraham, R. Kumar, S. Pattanayak, A. Mohapatra, S.S. Rath, A. Patra, H. Adikesavalu, N. Sood, P.K. 
Pradhan, B.K. Das, P. Jayasankar and J. K. Jena: Detection of goldfish haematopoietic necrosis herpes virus (Cyprinid herpesvirus-2) with multi-drug resistant Aeromonas hydrophila infection in goldfish: First evidence of any viral disease outbreak in ornamental freshwater aquaculture farms in India. Acta Trop., 161, 8-17 (2016).

Saitou, N. and M. Nei: The neighbor-joining method: a new method for reconstructing phylogenetic trees. Mol. Biol. Evol., 4, 406-425 (1987).

Shahraki, A.H., P. Heidarieh, M. Drancourt, M. Hashemzadeh and S. Khandan: Infection caused by an unusual isolate of nontuberculosis mycobacteria in Iran. Int. J. Mycobacteriol., 4, 162 (2015).

Sood, N., T.R. Swaminathan, M.K. Yadav, P.K. Pradhan, R. Kumar and N.K. Sood: First report of cutaneous infiltrative lipoma in goldfish Carassius auratus. Dis. Aquat. Org., 125, 243-247 (2017).

Talaat, A.M., R. Reimschuessel, S.S. Wasserman and M. Trucksis: Goldfish, Carassius auratus, a novel animal model for the study of Mycobacterium marinum pathogenesis. Infect. Immun., 66, 29382942 (1998).
Talaat, A.M., R. Reimschuessel and M. Trucksis: Identification of mycobacteria infecting fish to the species level using polymerase chain reaction and restriction enzyme analysis. Vet. Microbiol., 58, 229-237 (1997).

Tu, X., F. Ling, A. Huang and G. Wang: The first report of Dactylogyrus formosus Kulwiec, 1927 (Monogenea: Dactylogyridae) from goldfish (Carassius auratus) in central China. Parasitol. Res., 114, 2689-2696 (2015).

Ulrichs, T. and S.H. Kaufmann: New insights into the function of granulomas in human tuberculosis. J. Pathol., 208, 261-269 (2006).

Uma, A. and B.S. Ronald: Drug resistance in Mycobacterium fortuitum isolated from gold fish, Carassius auratus. Int. J. Environ. Sci. Technol., 5, 4411-4417 (2016).

Verma, D.K., G. Rathore, P.K. Pradhan, N. Sood and P. Punia: Isolation and characterization of Flavobacterium columnare from freshwater ornamental goldfish Carassius auratus. J. Env. Biol., 36, 433-439 (2015).

Wongsathein, D.: Fibromas in goldfish (Carassius auratus): A case report. Chiang Mai Veterynary, 4, 157-163 (2006). 